\title{
6
}

\section{Readiness Model for Integration of ICT and CPS for SMEs Smart Logistics}

\author{
Sakgasit Ramingwong, Lachana Ramingwong, \\ Trasapong Thaiupathump, and Rungchat Chompu-inwai
}

\subsection{Introduction}

Industry 4.0 has broadened the gap between modern and traditional small- and medium-sized enterprises (SMEs). Industry 4.0 involves application of a number of the most advanced technologies (Lasi et al. 2014) in all areas, including logistics. Logistics management involves

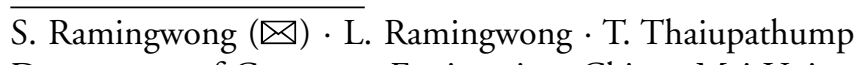
Department of Computer Engineering, Chiang Mai University, 239 Huay Kaew Road, Muang District, 50200 Chiang Mai, Thailand e-mail: sakgasit@eng.cmu.ac.th

L. Ramingwong e-mail: lachana.ramingwong@cmu.ac.th

T. Thaiupathump

e-mail: trasapong@eng.cmu.ac.th

S. Ramingwong

Center of Excellence in Logistics and Supply Chain Management, Chiang Mai University, 239 Huay Kaew Road, Muang District, 50200 Chiang Mai, Thailand 
planning, implementing, and controlling the efficient, effective forward and reverse flow and storage of goods, services, and related information from one point to another according to customers' requirements (CSCMP 2020). It is not just a process of transportation, but many activities are also involved in the logistics process. It is an integrating function, which coordinates and optimizes all logistics activities, as well as integrates logistics activities with other activities (CSCMP 2020).

Due to constantly changing customer needs, traditional logistics may not be able to meet more complicated customer requirements. Barreto et al. (2017) defined "Smart Logistics" as a logistics system that can increase flexibility and make adjustments to meet the changing needs of customers. Smart logistics is technology-driven. Flexibility, adaptability, and proactivity are more important than before and can only be achieved by integration of new technologies (Uckelmann 2008).

Information and Communication Technology (ICT) and CyberPhysical Systems (CPS) have been integrated for smart logistics (Schrauf and Berttram 2016). ICT refers to the integrations of devices, networking components, applications, and systems that allow people and organizations to exchange the information. CPS can be generally defined as the integrations of computation, networking, and physical processes that enables a physical system to be closely monitored, controlled by a computer algorithm (Lu 2017). In Industry 4.0, numerous industrial CPS-based applications have been developed and deployed. Building efficient connectivity of the CPS and external systems is quite challenging. A conceptual framework for enabling the connectivity of cyber-physical production systems inside smart factories is proposed by Rojas et al. (2017). Lee et al. (2015) proposed a functional model called 5C architecture for CPS. This model defines 5 levels of CPS functions and then provides a guideline for construction of a CPS. Similar to 5C, Porter and

R. Chompu-inwai

Department of Industrial Engineering, Chiang Mai University, 239 Huay Kaew Road, Muang District, 50200 Chiang Mai, Thailand e-mail: rungchat@eng.cmu.ac.th 
Heppelmann (2014) suggested building a connectivity-based infrastructure. The capability model advised by Hernández and Reiff-Marganiec (2014) suggests how CPS can be improved.

"Logistics 4.0" is focused on the specific applications of Industry 4.0 in logistics (Amr et al. 2019; Facchini et al., 2020). In addition, Barreto et al. (2017) also defined Logistics 4.0 as the combination of using logistics with innovations and applications of CPS. Winkelhaus and Grosse (2019) defined Logistics 4.0 as "the logistical system that enables the sustainable satisfaction of individualized customer demands without an increase in costs and supports this development in industry and trade using digital technologies."

Although smart logistics is one of the essential elements which are critical to survive in this highly competitive system, investing in technologies can be a double-edged sword for SMEs. It is important to keep all business dimensions balanced. Self-evaluation of an organization's own readiness for integrating technologies for smart logistics is important. From previous research studies, it was found that there have been several proposed readiness models based on different perspectives and different levels of implementation (Schumacher et al. 2016; Maasouman and Demirli 2015; Akdil et al. 2018; Gökalp et al. 2017). This research proposes a novel readiness model which can be used to evaluate readiness for integration of ICT and CPS for smart logistics. The model proposed in this chapter can be used as a guideline for organization assessment which aims to evaluate their technological readiness for smart logistics, particularly for SMEs. Therefore, they can accordingly make decisions on further investment.

\subsection{Related Works}

Numerous Industry 4.0 maturity and readiness models on different perspectives have been proposed since the term Industry 4.0 was introduced in 2015. Some of the well-recognized models are IMPULS (2015), Industry 4.0/Digital Operations Self-Assessment by $\mathrm{PwC}$ (2016), the Connected Enterprise Maturity Model by Rockwell Automation (2016), and the Industry 4.0 Maturity Model by Schumacher et al. (2016). 
IMPULS-Industrie 4.0 readiness model, proposed by Lichtblau et al. in 2015, consists of six levels of Industry 4.0 readiness: 0outsider, 1-beginner, 2-intermediate, 3-experienced, 4-expert, and 5-top performer, and six Industry 4.0 dimensions: strategy and organization, smart factory, smart operations, smart products, data-driven services, and employees. This model is an example of models focusing on technological aspects. The IMPULS model considers logistics operations within the context of the vertical and horizontal integration involving several company's departments and hierarchical levels (Lichtblau et al. 2015).

The digital operations self-assessment for Industry 4.0 was proposed by $\mathrm{PwC}$ in 2016. PwC provided a maturity model for companies to assess their capabilities. PwC's maturity model was organized in four stages and seven dimensions. Four stages are (1) digital novice, (2) vertical integrator, (3) horizontal collaborator, and (4) digital champion. Vertical integration is the integration of IT systems at multiple hierarchical manufacturing and production levels into one complete solution, whereas horizontal integration is the integration of IT systems across the multiple business planning and production processes. This model assesses companies' level of maturity with seven dimensions: digital business models and customer access, digitization of product and service offerings, digitization and integration of vertical and horizontal value chains, data and analytics as core capability, agile IT architecture, compliance, security, legal and tax, organization, employees, and digital culture. $\mathrm{PwC}$ provides an online self-assessment tool that enables companies to assess their level of Industry 4.0 maturity (Geissbauer et al. 2016).

The connected enterprise maturity model was proposed by Rockwell Automation in 2014. This model consists of five stages and four technology-oriented dimensions. Maturity stages in this model are (1) assessment; (2) secure and upgraded network and controls; (3) defined and organized working data capital (WDC); (4) analytics, and (5) collaboration. This model primarily focuses on four dimensions of OT/IT (Operations Technology/Information Technology) network: information infrastructure (hardware and software), controls and devices (sensors, actuators, motor controls, switches, etc.) that feed and receive data, networks that move all of this information and security policies (understanding, organization, enforcement) (Rockwell Automation 2014). 
The Industry 4.0 maturity model proposed by Schumacher et al. (2016) has nine dimensions and sixty-two maturity items in assessing companies Industry 4.0 maturity levels. Nine dimensions are strategy, leadership, customers, products, operations, culture, people, governance, and technology. Maturity levels are investigated under five levels, from level 1 to 5 .

Since the term Logistics 4.0 was coined in 2016, several maturity models for Logistics 4.0 have been proposed (Sternad et al. 2018; Oleśków-Szłapka and Stachowiak 2018; Facchini et al. 2020). Sternad et al. (2018) proposed the maturity levels for Logistics 4.0 based on NRW's Industry 4.0 maturity model (Kompetenzzentrum Mittelstand NRW 2020). The NRW's levels were defined based on the definition of automation in the Industry 4.0 concept. These levels also represent the evolution from separated software systems to networked systems. Sternad et al. (2018) used NRW's Industry 4.0 maturity model levels in identifying the maturity levels in four subsystems of logistics: purchase, production, distribution, and after-sales. Oleśków-Szłapka and Stachowiak (2018) defined three dimensions of Logistics 4.0: management, flow of material, and flow of information and also identified the areas of evaluation for each dimension. The five maturity levels of this model are ignoring, defining, adopting, managing, and integrated. Facchini et al. (2020) applied Oleśków-Szłapka’s Logistics 4.0 maturity model and verified the feasibility of this model in a real case study.

Compared to large-size companies, SMEs generally have less resources in adoption of Industry 4.0 technologies and concepts which is considered to be one of the key obstacles. Chatzoglou and Chatzoudes (2016) identified various factors affecting the adoption of Industry 4.0 technologies in SMEs. These factors involved adoption costs, competitive pressure, firm size, firm scope, CEO's knowledge, Internet skills, and IT infrastructure. There have been various studies focusing on the development of readiness/maturity models for SMEs and related issues (Ganzarain and Errasti 2016; Trotta and Garengo 2019; Rauch et al. 2020). Rauch et al. (2020) proposed a maturity level-based assessment tool to enhance the implementation of Industry 4.0 in SMEs. Some works focused on the logistics process in SMEs, such as a selfassessment of Industry 4.0 technologies focusing on the internal logistics 
Table 6.1 Readiness pillars and areas of evaluation

\begin{tabular}{ll}
\hline Readiness pillars & Areas of evaluation \\
\hline Production & $\begin{array}{l}\text { Products, facilities, operations, quality, real-time status, } \\
\text { automation, agility }\end{array}$ \\
Technology & Implementation, security, networking \\
People & People, stakeholders, culture \\
Logistics & Internal logistics, transportation \\
Strategy & Governance, strategy \\
\hline
\end{tabular}

for SMEs by Schiffer et al. (2019) and a requirement analysis for implementing smart logistics in SMEs by Dallasega et al. (2020). The results from this study involved: lean and agility; real-time status; digitization, connectivity, and network; tracking, PPC and WMS; culture, people, and implementation; security and safety; ease of use; transportation, and automation. This chapter expands this concept and systematically constructs a model for self-investigating for readiness in emerging SMEs.

\subsection{Readiness Model for Integration of ICT and CPS for Smart Logistics}

Based on the aforementioned research, all factors are analyzed and revised into 5 pillars, i.e. production, technology, people, logistics, and strategy. Each of them is further classified into a specific process area. Each readiness pillar and dedicated evaluation areas are depicted in Table 6.1. Detailed explanations of each process area as well as their objectives and passing criteria are subsequently described in the next section.

\subsection{Stages of Readiness}

Five stages of readiness, i.e. initial, trial, organized, automated, and optimized, are proposed in this chapter as shown in Table 6.2.

Table 6.2 illustrates the level of readiness and relevant process areas. There is only one process area on the product for the first level of 


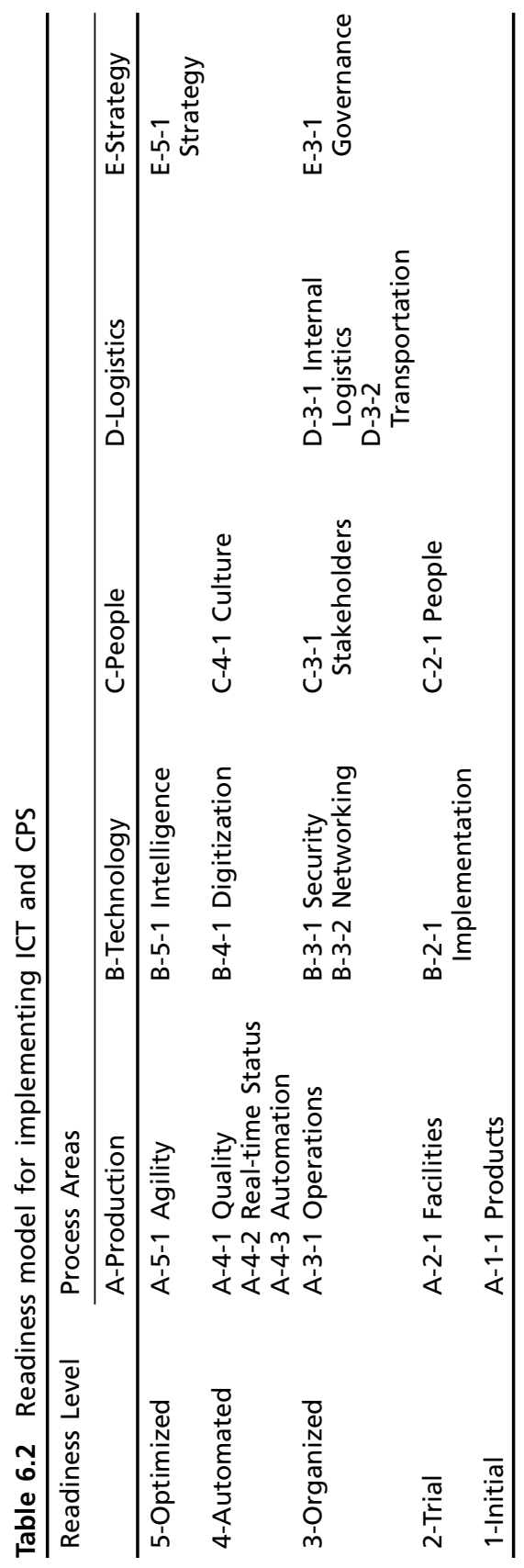


readiness. Then, basic resources of the organization are the core maturity of the second level. The third level of readiness explores the overall production, technology, people, logistics, and strategy. More advanced implementation of technology is evaluated in the fourth level. Finally, the fifth readiness level depicts the optimized utilization of technology.

The organization needs to satisfy every criterion of each process area to secure its readiness level. The first stage, initial, is essentially a preparation stage for organizations who are interested in implementing ICT and CPS.

\section{1-Initial}

Only one process area, i.e. A-1-1 Products, is identified at this level. An organization needs to at least understand basic requirements and purposes of the ICT and CPS implementation. Indeed, this is the first stage of investing and implementing technology in general. Although noting concrete is found in this early level, it projects a critical direction for the organizations.

Readiness: The organizations on this readiness level are not yet ready for advanced investment in technology. They should initially investigate their own needs and consult experts accordingly.

\section{2-Trial}

The second stage of the readiness model highlights an organization beginning its investment in ICT and CPS. Three major resources, infrastructure, implementation of technology, and people, are investigated in this stage. At this stage, technology is widely used in the organizations. However, numbers of deficiencies and repeated trials and errors are expected. The organizations which satisfy all requirements in this level are recognized as the beginners who are ready to excel in smart technologies in the near future.

Readiness: The organizations on this readiness level have basic experience on utilizing technology. However, they are still in an initial stage. Investment can slowly be made on the areas which they are familiar with. Consultancy from experts is still needed.

\section{3-Organized}

After a period of implementing technologies, the organizations begin to seek standardization of their processes. This level of readiness encapsulates 7 process areas which cover all of the 5 pillars. The organizations 
which achieve this level of readiness are familiar with the technologies and begin to expand their benefits to a larger scope of operations. Logistics begins to be a core strength. Production of these organizations has become stable. Deficiency can be found occasionally.

Readiness: The organizations are equipped with experiences and expertise on utilizing technology in several areas. Computer systems have become an important part in their core business. They are ready for more advanced technology.

\section{4-Automated}

The manufacturing lines in these organizations are stable. Production can be accurately forecasted. Higher technologies such as robotics and automation are fully utilized. Errors and defects are less likely to occur. The organizations also begin to build up their own learning cultures. Data begins to be one of important assets, although it has not yet been fully utilized.

Readiness: The organizations utilize automated systems in several areas of core competencies. They also efficiently utilize their knowledge base and are ready to upgrade themselves for intelligent technologies.

\section{5-Optimized}

The highest level of readiness depicts organizations which fully utilize technology. With strong culture and proactive organizational strategy, they are ready to implement any technologies for Industry 4.0 and are likely to succeed systematically. The organization also becomes heavily data-oriented. Standards are continuously evaluated and improved. The production lines are fully optimized. Very few errors or deficiencies can be found, and irregularly.

Readiness: The organizations have matured in their use of technology. The organizations are heavily data- and knowledge-driven. Intelligent systems have been implemented and efficiently utilized. They are ready for implementation of any unfamiliar technologies.

\subsection{Readiness Process Areas}

This section explains more detailed information on each process area following respective readiness pillars, as shown in Table 6.2. 


\section{A. Production}

Production is the backbone of this readiness model. It evaluates the entire life cycle of manufacturing by determining the maturity of relevant elements. A-1-1 Products, A-2-1 Facilities, A-3-1 Operations, A-4-1 Quality, A-4-2 Real-time Status, A-4-3 Automation, and A-5-1 Agility are specific process areas of this pillar. The advancement in this readiness level clearly depicts advancement in implementation of technologies.

\section{A-1-1 Products}

Products is the single starting point of readiness proposed by this chapter. This process area studies the feasibility as well as investigates the potential improvement of products and production lines using ICT and CPS (Schumacher et al. 2016). The organization needs to conduct a background inspection on the product life cycle and determine whether implementing ICT and CPS could be beneficial. Although the implementation of ICT and CPS is generally beneficial for most products, its effectiveness depends on many factors.

The organization needs to analyze what, when, where, who, and how ICT and CPS can improve its products and product lines. Different products may receive different benefits from the same approach. For example, implementing ICT and CPS may improve the quality of product $A$ while the same application cannot provide significant changes to product B. Additionally, areas of improvement should also be identified with clear and achievable indicators. Examples of these indicators are increased production speed, increased quantity, improved product quality, reduced defects, and improved visibility of production processes.

Although technical and financial feasibility plays a more important role for this process area. Other feasibility dimensions such as strategic, environmental, legal, schedule, safety, and resources should not be overlooked.

Objectives: To investigate the feasibility of implementation ICT and CPS.

Passing Criteria: Products and production lines which are suitable for and will be beneficial from implementation of ICT and CPS.

\section{A-2-1 Facilities}

Maturity of manufacturing infrastructure is a critical foundation of Industry 4.0. Even though the organizations have a strategic plan and suitable products for implementation, without a suitable infrastructure, 
implementing advanced technology can be extremely challenging. This process area involves availability of computer equipment, appropriateness of technology, and adequate spacing for automation (Maasouman and Demirli 2015). Network connectivity is not considered in this process area. Therefore, these facilities can be disconnected from each other. Inspection for adequateness should be conducted from strategic and technical perspectives.

A facility management process is also required for this process area. The main role of facility management is to monitor and maintain routine activities. A reporting mechanism and facility knowledge base are favorable for providing and communicating with stakeholders in case that undesirable events surface. Data from facility management can subsequently be used for strategic planning.

Objectives: To ensure that the organization has adequate facilities and facility management for integration of ICT and CPS.

Passing Criteria: Adequate and appropriate facilities and facility management for implementing ICT and CPS.

\section{A-3-1 Operations}

As the level of readiness increases, standards of operations need to be clearly defined. These standards should be developed and documented. Technologies are actively introduced at this stage. Although the utilization of ICT and CPS may be far from maturity, long-term plans or roadmaps for automating the operations are obviously preferred.

This process area focuses on all core business functions of the organizations, regardless of their relevance to ICT and CPS (Dallasega et al. 2020; Maasouman and Demirli 2015). Examples of these functions include accounting, researching, servicing, training, etc. In order to satisfy this process area's requirements, all relevant business functions need to be organized and visible. Their input, output, measurement, and responsibilities need to be systematically defined. This information will later assist in progressing to higher levels of readiness.

Objectives: To define core business operations.

Passing Criteria: Adequate documentation on core business operations.

\section{A-4-1 Quality}

At the fourth level of readiness, production processes are largely organized and standardized. Consequently, the focus of the pillar turns to 
quality. It is undeniable that quality of the products usually increases after the implementation of ICT and CPS systems (Maasouman and Demirli 2015). However, the organizations still need to define the desired level of quality for both products and production line. Indeed, needs for higher quality usually require higher investment in technology in both short and long terms.

In order to achieve desirable quality, ICT and CPS should be used as the major mechanisms to collect and analyze data from the production lines. This can be used to identify and subsequently resolve production problems.

Objectives: To investigate the desired level of quality of products and product line.

Passing Criteria: A balance in quality expectation and investment on ICT and CPS.

\section{A-4-2 Real-Time Status}

With a computerized system, monitoring and collecting data from the production lines as well as other business operations in real time become critical options to increase business competitiveness (Dallasega et al. 2020). These digital feedbacks can not only be used to improve the overall performance of the manufacturing, but also to make strategic decisions. Indeed, achieving real-time collection of data involves a certain level of investment. Therefore, the organizations may need to clearly prioritize on areas which have the most potential to gain benefit from this system.

Utilizing real-time status at this level of technological readiness spans throughout the entire supply chain. This means not only internal logistics, but information from suppliers and customers can also play important roles in this process area. Appropriate usage of real-time status can help the organizations to gain massive competitive advantages over their competitors, at the same time that it can help reduce unnecessary expenses.

Objectives: To make use of real-time data in improving operational efficiency.

Passing Criteria: A process of analyzing real-time data and examples of utilizing them in strategic decision-making or proactive planning. 


\section{A-4-3 Automation}

Robotics and automation usually involve major investments (Dallasega et al. 2020). However, although they generally provide benefits to the organization, maximizing performances from these technologies is challenging. Implementing automation requires various areas of expertise and experience. The Integration of ICT and CPS is a backbone to the core production line in the organization at this stage. With this process area, the organizations are expected to have higher productivity, higher accuracy, and lower defects.

Due to the high cost of investment, the organizations may begin the implementation of automation on a smaller scale for the core business competencies. This can help them to steadily manage changes as well as expectations from stakeholders.

Disruption from the implementation of automation is also expected, especially from employees. This ranges from personal stress to major resistance. The organization needs to prepare and manage these negative forces. The balance between technology and humanity is key for a sustainable future.

Also in this stage, the organizations should begin to collect data from automated processes. These data can be used for forecasting productivity, improving overall performance, and making decisions. They are also essential for the next level of technological maturity.

Objectives: To gain the benefits of automation in terms of productivity, visibility, and reduced deficiencies.

Passing Criteria: An automated production line with adequate data collecting mechanism.

\section{A-5-1 Agility}

At the final stage of maturity, the organizations expand their focus toward optimization, agility, and leanness. Unnecessary activities are restructured (Dallasega et al. 2020; Maasouman and Demirli 2015). All resources are used at their maximum capacity. Knowledge bases are maintained. The organizations also have adequate flexibility to handle any unexpected scenarios and requirements.

Agility also encourages innovations and continuous improvement. These are essential characteristics which improve long-term business competitiveness. 
Objectives: To maximize the use of organizational resources and capital. line.

Passing Criteria: A prototype of an efficient logistics system in a production

\section{B. Technology}

Technology pillar highlights the readiness of infrastructure, equipment, as well as technological protocols implemented in the organizations. It is involved in the second through the final stage of this readiness model.

\section{B-2-1 Implementation}

As for the second level of the readiness, technology is in the early introductory stage. However, the organizations need to adequately prepare relevant basic infrastructure and equipment. This usually includes a computer system and specialists (Dallasega et al. 2020). Implementation is at least done in offline mode and a number of trials and errors are expected.

A basic computer system includes hardware, software, and network equipment. Other relevant machinery such as robotics, conveyor belts, sensors, and other CPS can also be counted toward technological assets. The organizations need to learn to utilize this equipment in real production environments.

At this stage, the implementation of technology is in an introductory phase. However, the organizations need to inspect and cultivate lessons learnt from the process. With this knowledge, the organization will be able to efficiently identify and plan for long-term utilization of technology.

Objectives: To learn to utilize technology in a production line.

Passing Criteria: A production line which has technology successfully implemented.

\section{B-3-1 Security}

With more mature implementation of technology, more critical information is digitized. As a result, the organizations need to establish standards to secure their information (Dallasega et al. 2020).

Appropriate and adequate security and safety mechanisms need to be implemented to the system. The organizations should seek the latest and most secure standards to date. Additionally, an update interval needs 
to be scheduled to make sure that all information is secured. Backup systems are required for critical digital units.

Physical safety is also another important facet of this process area. All computer equipment needs to be secured in an appropriate space which is shielded from theft, fire, flood, or other disasters.

Objectives: To ensure that adequate security mechanisms have been implemented and maintained.

Passing Criteria: Appropriate and adequate security measures are implemented and maintained.

\section{B-3-2 Networking}

Networking of computer systems is an essential step toward digitization (Dallasega et al. 2020). At the third stage of readiness, all critical systems must be networked. This allows more efficient and accurate data collection which will be used in higher levels of technological readiness.

Redundancy systems are also preferable for this process area. In scenarios which online activities are crucial, the organizations may consider subscribing to more than one Internet or technology providers. This therefore provides redundancy to the core business functions.

Objectives: To ensure the stability and redundancy of networking systems.

Passing Criteria: A network system which has appropriate structure and redundancy.

\section{B-4-1 Digitization}

At the fourth stage of readiness, the organizations have become largely digitized. Old-fashioned paper-based documentation is converted to computerized systems (Dallasega et al. 2020; Chatzoglou and Chatzoudes 2016). Information is visible, secured, and accurate. The organizations begin to use this information in strategic planning and decisionmaking.

Objectives: To utilize the digitized core business function.

Passing Criteria: A core business function is digitized and its data is used in strategic planning.

\section{B-5-1 Intelligence}

At the final stage of readiness, the manufacturing becomes intelligent. All core processes are data-driven. Machine learning and other computational intelligence become the backbone of the organization. 
This further increases the efficiency and effectiveness of logistics and other core business functions.

Objectives: To utilize business intelligence to continuously improve core business functions.

Passing Criteria: An appropriate utilization of intelligence on core business functions.

\section{People}

People is undeniably one of the most crucial capitals in modern businesses. Managing people can be extremely difficult especially when unfamiliar scenarios are introduced. This readiness pillar highlights the relevant people and their required quality in implementation of digital systems.

\section{C-2-1 People}

This process area focuses on internal staff. Indeed, in order to successfully implement advanced technology, people with the appropriate experience and expertise are required (Dallasega et al. 2020; Maasouman and Demirli 2015; Schumacher et al. 2016). Although external experts can be sought, the organizations need to appoint internal staff on at least basic solutions and maintenance of computer systems. This is to ensure that these systems can be regularly used for supporting relevant business functions.

Training is an important investment for this process area. This is specifically true when new technologies are introduced or procured. The organizations should consider both short- and long-term training for their employees. Although training can be costly, it usually provides greater benefits in the long run.

Another challenging aspect of implementing technology is a method to sustain staff's morale. It is obvious that staff, especially older and less technologically experienced employees, are likely to fear technology. Minor resistance to major disruptions can be a result of this. The organizations need certain mechanisms to lessen these potential struggles.

Objectives: To ensure that adequate staffing is allocated for technology division.

Passing Criteria: Adequacy in numbers and quality of staff for technologyrelated tasks. 


\section{C-3-1 Stakeholders}

The focus of people in the third stage of readiness expands to external stakeholders (Schumacher et al. 2016). Due to the more implementation of technology, the organizations need to improve their communication channels in which they can cope up with digital information more appropriately. In the same way, their major stakeholders are expected to use the same level of technology. Similar to other process areas, this helps coordination between stakeholders to become more effective, efficient, accurate, and visible.

An important key to establishing effective communication between the organizations and their stakeholders is standards. There are a number of standards which are widely implemented by leading organizations. This needs to be agreed upon by their counterparts.

Objectives: To ensure that there is a standard for communicating with stakeholders.

Passing Criteria: A standard for communication between stakeholders.

\section{C-4-1 Culture}

The highest level process area of people pillar is culture. It is important for the organization to establish a culture which encourages and embraces changes, especially for technology (Dallasega et al., 2020; Schumacher et al. 2016). Indeed, the speed of change in technology is gradually increasing. Lagging behind can have the cost of a major reduction in business competitiveness. To prevent this, the organization needs to continuously update its digital capital as well as educate its human resources.

Knowledge is a critical element for maintaining culture in the organization. It can be used as the main media to share and transfer culture between staff and stakeholders.

Objectives: To build a culture which embraces implementation of technology.

Passing Criteria: A mechanism which lays the foundations for knowledge sharing and culture sustaining.

\section{Logistics}

The logistics pillar highlights all essential business processes regarding logistics and supply chain management. 


\section{D-3-1 Internal Logistics}

At the third stage of technological maturity, all internal logistics need to be structured and manageable. The visibility of core business functions is crucial for expanding to higher levels of readiness (Dallasega et al. 2020). Obviously, implementation of computer systems in the line of logistics can satisfy this need.

The use of ICT and CPS can immensely introduce a number of novel perspectives to the manufacturing. For example, the use of RFID can make the entire logistics become thoroughly visible. Moreover, the processes are faster and more manageable. Information from this can be used for more complex logistics functions such as strategic planning and forecasting.

Objectives: To digitize internal logistics function as a prototype.

Passing Criteria: A production line which has ICT and CPS implemented and has data collected.

\section{D-3-2 Transportation}

Technology and transportation have been intensively interrelated (Dallasega et al. 2020). The use of technology to improve the efficiency of transportation is required for this readiness level. Unlike the previous process area, which has internal focus, this process area highlights external logistics and the transportation of products.

Integrating ICT and CPS in transportation can noticeably improve visibility and manageability of the logistics. Similar to internal logistics, the transportation becomes more efficient and accurate. Information from this process area can be another critical input for a higher level of technological advancement.

Objectives: To digitize external logistics function as a prototype.

Passing Criteria: A transportation function which has ICT and CPS implemented and has data collected.

\section{E. Strategy}

The final pillar in this proposed readiness model involves strategy. This includes top-level management policy and strategy to build competitiveness and sustainability for the implementation of ICT and CPS.

\section{E-3-1 Governance}

At the third stage of readiness, the organizations need to have a certain level of governance. Governance includes policies on authorities, 
accountabilities, roles, and responsibilities of stakeholders involved by the organizations (Chatzoglou and Chatzoudes 2016; Maasouman and Demirli 2015; Schumacher et al. 2016). An effective governance policy can also help the organizations to be flexible and competitive.

A guideline for evaluating performance of technology utilization can be identified in the governance policy. This further improves the overall manageability of the organizations. It also helps in measuring, evaluating, and judging events which may surface later.

Objectives: To ensure the availability and implementation of a digital governance.

Passing Criteria: An adequate digital governance policy.

\section{E-5-1 Strategy}

This process area highlights a long-term plan on integration of ICT and CPS for the organization. Similar to business strategy, technology strategy leads the direction of development of digital transformation (Chatzoglou and Chatzoudes 2016; Schumacher et al. 2016). Relevant technologies, governance framework, and implementation policy should be continuously reviewed and revised on a timely basis.

Strategy has to be based on facts from data cultivated from all other process areas in the lower level of readiness model. With actual data, planning is likely to be more accurate and the implementation is likely to be more efficient. Several levels of strategy, e.g. short-term, mediumterm and long-term, may be needed according to business needs and competition.

Objectives: To establish a strategy for integration of ICT and CPS. Passing Criteria: An adequate strategy based on actual data.

\subsection{Conclusion and Outlook}

The proposed model can be used for assessing the readiness of integration of ICT and CPS for organizations. Five essential pillars of readiness have been identified, which are production, technology, people, logistics, and strategy. Each pillar encapsulates several process areas. The organizations need to satisfy the objectives and passing criteria in order to accredit each process area. The readiness model is classified into 5 levels. 
The first level is the initial stage of technology implementation. In order to achieve this level, the organizations need to understand the potential of their products and conduct a basic feasibility study. As for the second level of readiness, the organizations begin their pilot integration. This includes several ad hoc processes which may result in errors and defects. Yet, it is an important stage which builds the foundations for more advanced technologies to be implemented later. The third stage of readiness defines the organizations which have already established the utilization of ICT and CPS in production lines. Although deficiencies can be regularly found, the organizations appear to realize the benefits of technology and aim to further utilize it in the future. As for the fourth stage of the readiness, the organizations build up their knowledge base and partly automate core business processes. Finally, the final stage identifies the organizations which optimize their technological usage and continuously improve their perspectives. In order to acquire a level of readiness, all process areas in that and lower levels need to be achieved.

This readiness model is suitable to be adopted by SMEs or larger organizations. Depending on the size, focus, and market, SMEs can use the objective and passing criteria identified in each process area to evaluate their readiness. The model will help SMEs to investigate their incompetencies, which they can address later.

\section{References}

Akdil, K.Y., Ustundag, A., and Cevikcan, E. 2018. Maturity and Readiness Model for Industry 4.0 Strategy. Industry 4.0: Managing The Digital Transformation, Springer Series in Advanced Manufacturing. Springer, Cham. https://doi.org/10.1007/978-3-319-57870-5_4.

Amr, M., M. Ezzat, and S. Kassem. 2019. Logistics 4.0: Definition and historical background. Novel Intelligent and Leading Emerging Sciences Conference (NILES) 2019: 46-49. https://doi.org/10.1109/NILES.2019.8909314.

Barreto, L., A. Amaral, and T. Pereira. 2017. Industry 4.0 implications in logistics: An overview. Procedia Manufacturing 13: 1245-1252. https://doi.org/ 10.1016/j.promfg.2017.09.045. 
Chatzoglou, P., and D. Chatzoudes. 2016. Factors affecting e-business adoption in SMEs: An empirical research. Journal of Enterprise Information Management 29 (3): 327-358. https://doi.org/10.1108/JEIM-03-2014-0033.

Council of Supply Chain Management Professionals (CSCMP). 2020. CSCMP's Definition of logistics management. https://cscmp.org Accessed on August 13, 2020.

Dallasega, P., Woschank, M., Zsifkovits, H., Tippayawong, K., Brown, C.A. 2020. Requirement analysis for the design of smart logistics in SMEs. In Matt D., Modrák V., Zsifkovits H. (eds.) Industry 4.0 for SMEs. Palgrave Macmillan, Cham. https://doi.org/10.1007/978-3-030-25425-4_5.

Facchini, F., J. Oleśków-Szłapka, L. Ranieri, and A. Urbinati. 2020. A maturity model for logistics 4.0: An empirical analysis and a roadmap for future research. Sustainability 12 (1): 86. https://doi.org/10.3390/su12010086.

Ganzarain, J., and N. Errasti. 2016. Three stage maturity model in SME's toward industry 4.0. Journal of Industrial Engineering and Management (JIEM) 2016-9 (5): 1119-1128. https://doi.org/10.3926/jiem.2073.

Geissbauer, R., Vedso, J., Schrauf, S. 2016. Industry 4.0: Building the digital enterprise. https://www.pwc.com/gx/en/industries/industries-4.0/landingpage/industry-4.0-building-your-digital-enterprise-april-2016.pdf. Accessed on July 30, 2020.

Gökalp, E. Sener, U., and Eren, P. 2017. Development of an assessment model for industry 4.0: Industry 4.0-MM. International Conference on Software Process Improvement and Capability Determination. https://doi. org/10.1007/978-3-319-67383-7_10.

Hernández, M.E.P. and Reiff-Marganiec, S. 2014. Classifying smart objects using capabilities. 2014 International Conference on Smart Computing, Hong Kong, 309-316. https://doi.org/10.1109/SMARTCOMP.2014.704 3873.

Kompetenzzentrum Mittelstand NRW. 2020. Quick check industrie 4.0 Reifegrad. https://indivsurvey.de/umfrage/53106/uHW7XM. Accessed on June 25, 2020.

Lasi, H., Fettke, P., Feld, T. and Hoffmann, M. 2014. Industry 4.0. Business \& Information Systems Engineering, 6(4), 239-242. https://aisel.aisnet.org/ bise/vol6/iss $4 / 5$.

Lee, J., B. Bagheri, and H.A. Kao. 2015. A cyber-physical systems architecture for industry 4.0-based manufacturing systems. Manufacturing Letters 3: 1823. https://doi.org/10.1016/j.mfglet.2014.12.001. 
Lichtblau, K., Stich, V., Bertenrath, R., Blum, M., Bleider, M., Millack, A., Schmitt, K., Schmitz, E., Schröter, M. 2015. IMPULS-Industrie 4.0Readiness. Impuls-Stiftung des VDMA, Aachen-Köln.

Lu, Y. 2017. Cyber Physical System (CPS)-based industry 4.0: A survey. Journal of Industrial Integration and Management. 2 (3): 1750014. https://doi.org/ 10.1142/S2424862217500142.

Maasouman, M.A., and K. Demirli. 2015. Assessment of lean maturity level in manufacturing cells. IFAC-PapersOnLine 48 (3): 1876-1881. https://doi. org/10.1016/j.ifacol.2015.06.360.

Oleśków-Szłapka, J., and A. Stachowiak. 2018. The framework of logistics 4.0 maturity model. Intelligent Systems in Production Engineering and Maintenance 771-781. https://doi.org/10.1007/978-3-319-97490-3_73.

Porter, M.E., and J.E. Heppelmann. 2014. How smart, connected products are transforming competition. Harvard Business Review 92 (11): 64-88.

Rauch, E., M. Unterhofer, R. Rojas, L. Gualtieri, M. Woschank, and D. Matt. 2020. A maturity level-based assessment tool to enhance the implementation of industry 4.0 in small and medium-sized enterprises. Sustainability. 12: 1-18. https://doi.org/10.3390/su12093559.

Rockwell Automation. 2014. The Connected Enterprise Maturity Model. https://iterature.rockwellautomation.com/idc/groups/literature/documents/ wp/cie-wp002_-en-p.pdf. Accessed on June 30, 2020.

Rojas, R., E. Rauch, R. Vidoni, and D.T. Matt. 2017. Enabling connectivity of cyber-physical production systems: A conceptual framework. Procedia Manufacturing 11: 822-829. https://doi.org/10.1016/j.promfg. 2017.07.184.

Schiffer, M., H.H. Wiendahl, and B. Saretz. 2019. Self-assessment of industry 4.0 technologies in intralogistics for SME's. IFIP International Conference on Advances in Production Management Systems (APMS) 339-346. https://doi. org/10.1007/978-3-030-29996-5_39.

Schrauf, S., and Berttram, P. 2016. Industry 4.0: How digitization makes the supply chain more efficient, agile, and customer-focused. https://www. strategyand.pwc.com/gx/en/insights/2016/digitization-more-efficient.html. Accessed on June 30, 2020.

Schumacher, A., S. Erol, and W. Sihn. 2016. A maturity model for assessing Industry 4.0 readiness and maturity of manufacturing enterprises. Procedia CIRP 52: 161-166. https://doi.org/10.1016/j.procir.2016.07.040.

Sternad M., Lerher T., and Gajšek B. 2018. Maturity Levels for Logistics 4.0 Based on NRW's Industry 4.0 Maturity Model. 18th international scientific conference Business Logistics in Modern Management. 695-708. 
Trotta, D., and Garengo, P. 2019. Assessing industry 4.0 maturity: An essential scale for SMEs. 2019 8th International Conference on Industrial Technology and Management (ICITM). https://doi.org/10.1109/ICITM.2019. 8710716.

Winkelhaus, S., and E.H. Grosse. 2019. Logistics 4.0: A systematic review towards a new logistics system. International Journal of Production Research 58 (1): 18-43. https://doi.org/10.1080/00207543.2019.1612964.

Uckelmann D. 2008. A definition approach to smart logistics. In Balandin S., Moltchanov D., Koucheryavy Y. (eds.) Next generation teletraffic and wired/wireless advanced networking. NEW2AN 2008. Lecture Notes in Computer Science, 5174. Springer, Berlin, Heidelberg. https://doi.org/10. 1007/978-3-540-85500-2_28.

Open Access This chapter is licensed under the terms of the Creative Commons Attribution 4.0 International License (http://creativecommons.org/ licenses/by/4.0/), which permits use, sharing, adaptation, distribution and reproduction in any medium or format, as long as you give appropriate credit to the original author(s) and the source, provide a link to the Creative Commons license and indicate if changes were made.

The images or other third party material in this chapter are included in the chapter's Creative Commons license, unless indicated otherwise in a credit line to the material. If material is not included in the chapter's Creative Commons license and your intended use is not permitted by statutory regulation or exceeds the permitted use, you will need to obtain permission directly from the copyright holder.

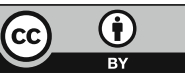

